\title{
Lost but eventually found: delayed removal of an intramyocardial bullet
}

\author{
Duncan Maguire, MD · Carly Lodewyks, MD, MSc • Michael H. Yamashita, MDCM, \\ MPH, FRCSC
}

Received: 27 August 2020/Revised: 24 September 2020/Accepted: 24 September 2020/Published online: 7 October 2020

(C) Canadian Anesthesiologists' Society 2020

A 22-yr-old male (who consented to this report) presented to the emergency department with a gunshot wound to the right chest. Because of an altered level of consciousness, hemodynamic instability, and a focused assessment with sonography in trauma exam showing a large pericardial effusion, the patient was taken to the operating room for an emergency sternotomy. After evacuating a large volume of blood from the anterior mediastinum and opening the pericardium, a small penetrating injury to the free wall of the right ventricle was repaired with pledgeted sutures. The remainder of the heart appeared to be free of injury. No bullet or other cardiac injury was identified on surgical examination or on transesophageal echocardiography (TEE). A postoperative chest $\mathrm{x}$-ray confirmed the intrathoracic presence of a retained bullet (Figure, panel A) and a computed tomography scan of the chest showed

Electronic supplementary material The online version of this article (https://doi.org/10.1007/s12630-020-01821-2) contains supplementary material, which is available to authorized users.

D. Maguire, MD $(\bowtie)$

Department of Anesthesia, Max Rady College of Medicine, University of Manitoba, Winnipeg, MB, Canada

e-mail: ummaguid@myumanitoba.ca

C. Lodewyks, MD, MSc - M. H. Yamashita, MDCM, MPH, FRCSC

Division of Cardiac Surgery, Department of Surgery, Max Rady

College of Medicine, University of Manitoba, Winnipeg, MB,

Canada

Cardiac Sciences Program, St. Boniface Hospital, Winnipeg, MB, Canada the bullet had lodged in the intraventricular septum (IVS) (Figure, panel B). A coronary angiogram was performed to exclude coronary artery injury, which also showed the bullet moving with each myocardial contraction (Figure, panel C; eVideo in the Electronic Supplementary Material). After carefully weighing the risks of repeat surgery versus the risks of potential complications from a retained bullet (e.g., bullet embolism, bullet erosion causing bleeding, or nidus for endocarditis or thrombus), the patient was brought back to the operating room ten days after the initial gunshot for bullet removal. A repeat intraoperative TEE identified the bullet within the right ventricular side of the IVS (Figure, panel D). Using cardiopulmonary bypass and cardioplegic arrest, the right ventricle was examined via a transtricuspid valve approach using a right atrial incision. The bullet was not easily found as it was completely embedded in the IVS, but was successfully removed and a small defect in the IVS was closed. No other cardiac injury was identified. The patient 


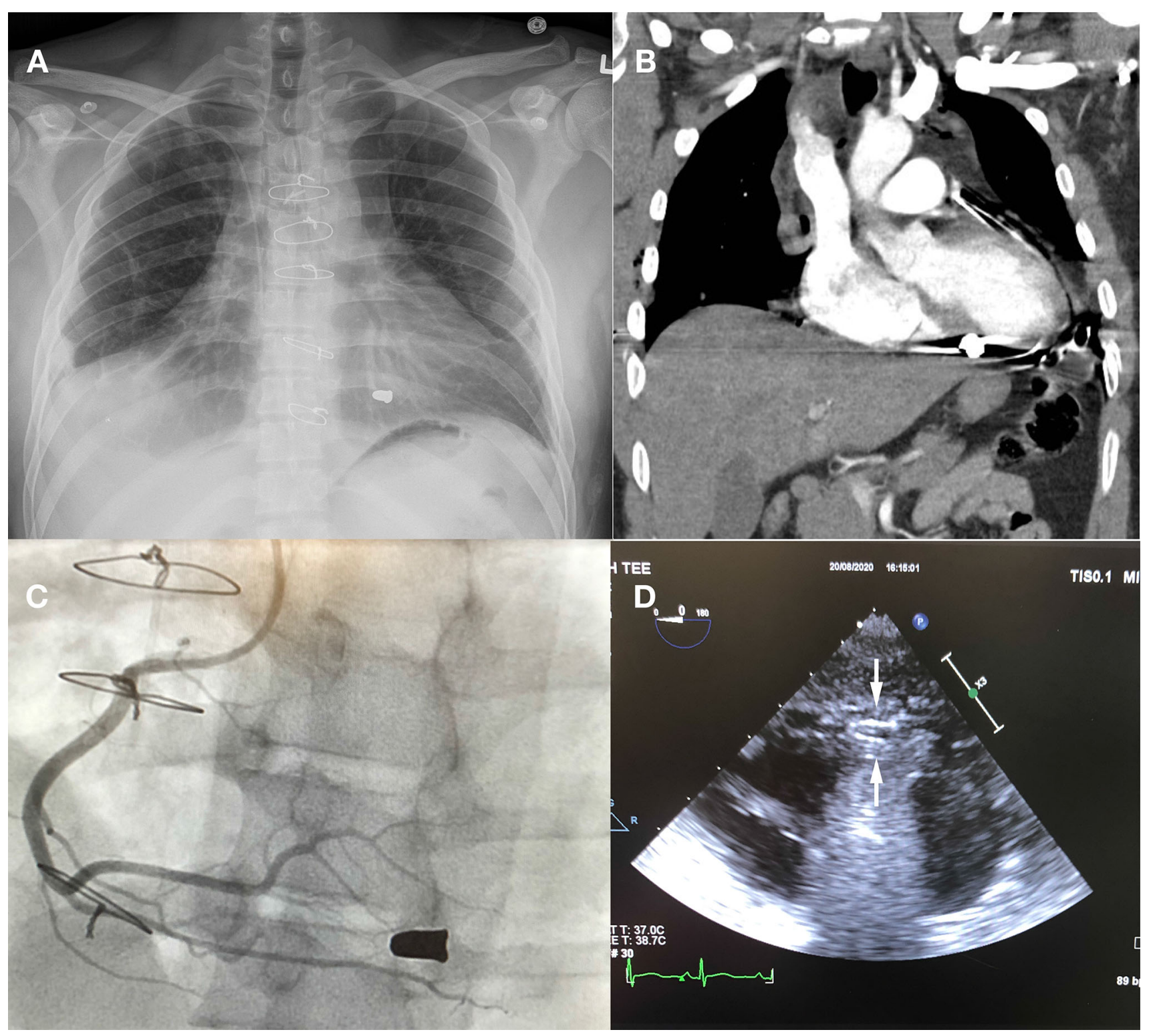

FIGURE A) Postoperative chest radiograph showing a retained intracardiac bullet. B) Postoperative computed tomography scan (coronal plane) of the chest showing a bullet in the intraventricular septum. C) Coronary angiogram of the right coronary artery showing

made a full recovery and was discharged from hospital with no complications.

Disclosures None.

\section{Funding statement None.}

no significant coronary artery involvement. D) Transesophageal echocardiogram in transgastric short axis view showing the bullet (white arrow) lodged in the intraventricular septum.

Editorial responsibility This submission was handled by Dr. Philip M. Jones, Associate Editor, Canadian Journal of Anesthesia.

Publisher's Note Springer Nature remains neutral with regard to jurisdictional claims in published maps and institutional affiliations. 